\title{
CUTANEOUS METASTASES OF FOLLICULAR CARCINOMA THYROID DIAGNOSED BY FINE NEEDLE ASPIRATION CYTOLOGY
}

Bharati Hunnur, Blessy Mary Thomas, Zulfikar Ahmed, Umaru. N.

1. Post Graduate Student. Department of Pathology, A. J. Institute Medical Sciences. Mangalore, Karnataka.

2. Post Graduate Student. Department of Pathology, A. J. Institute Medical Sciences. Mangalore, Karnataka.

3. Associate Professor. Department of Pathology, A. J. Institute Medical Sciences. Mangalore, Karnataka.

4. Professor \& HOD, Department of Pathology, A. J. Institute Medical Sciences. Mangalore, Karnataka.

\section{CORRESPONDING AUTHOR:}

Dr. Zulfikar Ahmed,

Associate professor, Department of Pathology,

A.J.I.M.S, Kuntikana, Mangalore, Karnataka.

E-mail: zulfikaraha@gmail.com

ABSTRACT: INTRODUCTION: Cutaneous metastasis of follicular carcinoma of thyroid is rare. There are fewer than 30 cases reported in the literature, majority affecting the scalp. CASE HISTORY: 55yrs old female presented with swelling over right side of the forehead. FNAC from the nodule showed uniform sized epithelial cells arranged in repetitive follicular pattern \& rosettes, suggestive of follicular carcinoma of thyroid. RESULTS: Morphological features of follicular carcinoma thyroid are unique in FNAC smears \& hence we came to the diagnosis of follicular carcinoma thyroid on FNAC of forehead nodule. DISCUSSION: Cutaneous metastasis explains the aggressive nature of the disease \& they have contributed to poor outcome. Average length of survival after diagnosis of cutaneous metastasis from follicular carcinoma thyroid is 19 months. CONCLUSION: We have presented an unusual case of aggressive follicular carcinoma thyroid with wide spread cutaneous metastases.

KEY WORDS: Follicular carcinoma, FNAC forehead, Cutaneous metastases

INTRODUCTION: Follicular carcinoma thyroid is the second most common thyroid malignancy following papillary carcinoma. There are fewer than 30 cases of cutaneous metastasis of follicular carcinoma thyroid reported in the literature, majority affecting the scalp. Follicular thyroid carcinoma is composed of normal-looking thyroid follicles with or without mild anaplasia. Diagnosis depends mainly on vascular or capsular invasion. ${ }^{1}$ When such invasion is failed to be detected, the first evidence of malignant follicular tumor may be appearance of distant metastasis generally to bone and lungs. ${ }^{1}$ Cutaneous metastasis from follicular thyroid carcinoma is rare and fine needle aspiration (FNA) is an important method for rapid diagnosis of such lesions.

CASE HISTORY: 55yrs old female presented with swelling over right side of the forehead (figure 1). CT head Showed lobulated enhancing isodense mass in right frontal region with erosion of adjacent calvarium \& extension into pericranial soft tissues. CT morphology was suggestive of metastases/lymphomas. FNAC from the nodule in the forehead was performed and the slides were stained by PAP stain and Leishman stain. FNAC from the nodule showed uniform sized epithelial cells arranged in repetitive follicular pattern \& rosettes, suggestive of follicular carcinoma of thyroid (Figure 2, 3). Later, detailed history was taken from the patient and got the history of total thyroidectomy done 10yrs back. 
DISCUSSION: Follicular carcinoma accounts for $10-20 \%$ of all thyroid cancers ${ }^{2}$. They tend to present in women with peak incidence in 40-50 years. Incidence of follicular carcinoma is increased in areas of dietary iodine deficiency, suggesting that nodular goiter may predispose to the development of the neoplasm. ${ }^{3}$ Metastases occur in less than $1 \%$ of the patients with the minimally invasive carcinomas with capsular invasion only, in less than $5 \%$ of those with vascular invasion, and in as many as $80 \%$ of those with widely invasive tumors. ${ }^{4,5,6}$ Distant metastases at the time of diagnosis are reported in $11-20 \%$ of patients \& may be the reason for presentation. Distant metastasis of follicular carcinoma can manifest after a period of 10 years. Most common sites of metastasis of follicular carcinoma thyroid are bones, lungs \& CNS. Follicular carcinoma of thyroid rarely metastasizes to skin, but when they do so, scalp is the site of predilection. However, cytology smears from thyroid mass as well as skin nodules show epithelial cell clusters forming microfollicles/rosettes in a repetitive manner consistent with well-differentiated follicular thyroid carcinoma with metastasis to skin. ${ }^{7}$ The overall rarity of cutaneous metastasis from follicular thyroid carcinoma is reflected by the presence of only 15 such cases previously reported in English language literature. ${ }^{8,9}$ However, only 2 cases of diagnosis of cutaneous metastases from follicular carcinoma thyroid by Fine Needle Aspiration Cytology have been reported ${ }^{2}$. Morphological features of follicular carcinoma thyroid are unique in FNAC smears \& hence we came to the diagnosis of follicular carcinoma thyroid on FNAC of forehead nodule. Cutaneous metastases explain the aggressive nature of the disease \& they have contributed to poor outcome. Average length of survival after diagnosis of cutaneous metastasis from follicular carcinoma thyroid is 19 months ${ }^{10}$.

CONCLUSION: We have presented an unusual case of aggressive Follicular carcinoma thyroid with wide spread cutaneous metastases. This patient has high risk, with probable poor prognosis for surgical management because of the extensive demonstrable radiographic skull involvement.

\section{REFERENCES:}

1. Hay ID. Follicular thyroid cancer. Endocrinol Metab Clin North Am 1995;24:761-802.

2. Agarwal S, Rao S, Arya A, Gupta K, Arora R, Dhawan I. Follicular thyroid carcinoma with metastasis to skin diagnosed by fine needle aspiration cytology. Indian J Pathol Microbiol 2008;51:430-1

3. Abbas AK. The endocrine system. In : Kumar V, Abbas AK, Fausto N, editors. Robbins and Cotran pathologic basis of disease. 7 th ed. New Delhi: Harcourt India Private Ltd; 2003. p. $1155-226$.

4. Cady B, Rossi R, Silverman M, Wool M: Further evidence of the validity of risk group definition in differentiated thyroid carcinoma, Surgery 98: 1171, 1985.

5. lida F: Surgical significance of capsule invasion of adenoma of the thyroid, Surg Gynaecol Obstet 144:710, 1977.

6. Lang W, Choritz H, Hundeshagen H: Risk factors in follicular thyroid carcinomas: a retrospective follow-up study covering a 14-year period with emphasis on morphological findings, Am J Surg Pathol 10:246, 1986

7. Penneys NS. Metastatic follicular carcinoma of the thyroid to the skin: A case confirmed by immunohistochemistry. J Cutan Pathol 1985;12:103-5. 
8. Dhal PR, Brodland DG, Goellnar JR, Hay ID. Thyroid carcinoma metastatic to the skin: A cutaneous manifestation of a widely disseminated malignancy. J Am Acad Dermatol 1997;36:531-7.

9. Quin TR, Duncan LM, Zembowicz A, Faquin WC. Cutaneous metastasis of follicular thyroid carcinoma: A report of four cases and a review of literature. Am J Dermatopathol 2005;27:306-12.

10. Rahman G A, Abdulkadir A Y, Olatoke S A, Yusuf I F, Braimoh K T. Unusual cutaneous metastatic follicular thyroid carcinoma. J Surg Tech Case Report 2010;2:35-8
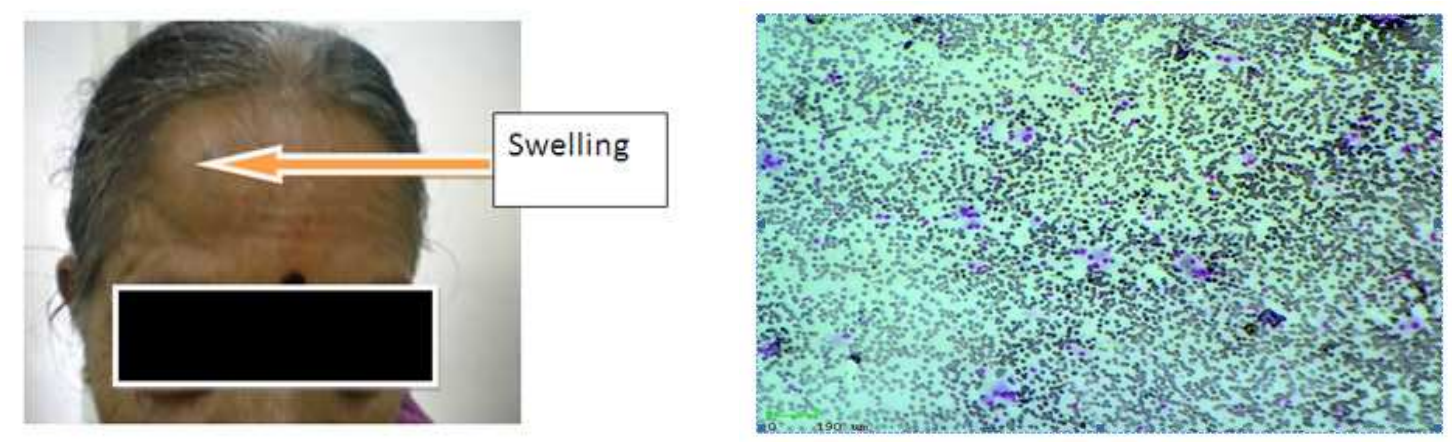

Figure 1: swelling in the forehead Figure 2: 10X FNAC smear showing repetitive microfollicles and rosettes in Follicular carcinoma thyroid

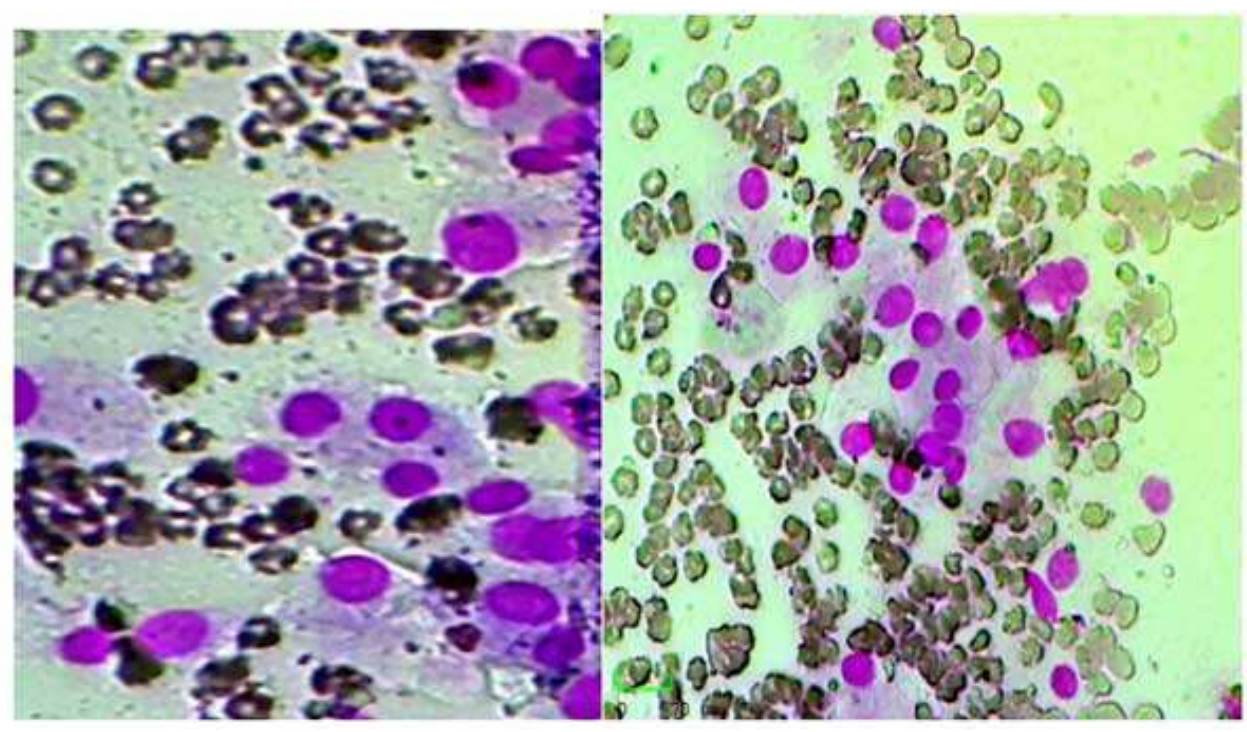

Figure 3: 40X FNAC smear showing uniform sized cells with mild nuclear atypia in Follicular carcinoma thyroid 